\title{
Potencial alelopático de Tropaeolum majus L. na germinação e crescimento inicial de plântulas de picão-preto
}

\author{
Allelophaty potential of Tropaeolum majus $\mathrm{L}$ on picão-preto seeds germination and initial \\ seedling growth
}

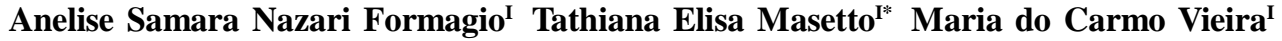 \\ Néstor Antonio Heredia Zárate ${ }^{\mathrm{I}}$ Willian Ferreira da Costa ${ }^{\mathrm{II}}$ Lucas Noboru Fatori Trevizan $^{\mathrm{I}}$ \\ Maria Helena Sarragiotto ${ }^{\text {II }}$
}

\section{RESUMO}

\begin{abstract}
Objetivou-se com este estudo avaliar o potencial alelopático de extratos metanólicos de folhas, flores e raízes de capuchinha (Tropaeolum majus L.) sobre a germinação de sementes e o crescimento inicial de plântulas de picão-preto. $O$ extrato metanólico com melhor potencial de inibição foi submetido a particionamento, resultando nas frações hexânica, clorofórmica, acetato de etila e hidrometanólica e posterior caracterização pelo espectro de absorção na região do infravermelho (IV). O efeito alelopático foi avaliado sobre as sementes de picão-preto, as quais foram distribuídas sobre papel germitest umedecido com $2 \mathrm{~mL}$ dos extratos e mantidas em germinador do tipo B.O.D. regulado a temperatura de $25^{\circ} \mathrm{C}$ e luz branca constante, sendo que as sementes imersas diretamente em água constituíram o tratamento controle. A avaliação da qualidade da semente foi realizada pelos testes de germinação e vigor (primeira contagem e comprimento de raiz primária e de hipocótilo das plântulas), em delineamento inteiramente ao acaso. O potencial alelopático das folhas de capuchinha foi maior em relação às demais partes da planta sobre a germinação das sementes, comprimento de hipocótilo $e$ de raiz das plântulas de picão-preto. Estes efeitos podem estar associados à presença de grupos químicos polares, pois à medida que se aumentou a polaridade dos solventes detectouse maior efeito inibitório sobre a germinação e o crescimento inicial de plântulas de picão-preto.
\end{abstract}

Palavras-chave: capuchinha, planta medicinal, efeito inibitório, grupos polares.

\section{ABSTRACT}

This research aimed to evaluate the metanolic extracts allelopathic potential from leaves, flowers and roots of capuchinha (Tropaeolum majus L.) on picão-preto seeds germination and initial seedling growth. The best inhibitor metanolic extract was fractioned, in hexanic, cloroformic, etil acetate and hidrometanolic fractions and it was characterized through absorption spectrum using mid-infrared. To evaluate the allelopathic effect of metanolic extracts and the fractions aftereffect; it was used picão-preto seeds distributed on $2 \mathrm{ml}$ extracts moistured paper maintained in B.O.D. germinator at $25^{\circ} \mathrm{C}$ and white constant light. Seeds sowed directly in water moistured germitest paper constituted the control. The allelopathic potential extracts were evaluated through the first count, final germination percentage, seedlings primary root and hypocotyl length $(\mathrm{cm})$. The experiment was carried out DIC with three replications of 25 seeds. The capuchinha leaves showed allelopathic potential on picão-preto seeds germination, hypocotyl and seedlings primary root length. It was suggested that such effects are associated to the presence of polar chemical groups because the increase in the solvents polarity detected the major picão-preto germination and seedlings growth inhibition effect.

Key words: capuchinha, medicinal plant, inhibition effect, polar groups.

\section{INTRODUÇÃO}

A infestação crescente de plantas daninhas nos sistemas agrícolas é um dos principais problemas enfrentados pelos agricultores, elevando o custo de produção por causar prejuízos às lavouras, com decréscimos acentuados da produtividade, quer pela competição direta por fatores de produção ou pelos compostos alelopáticos liberados no meio (SILVA et al., 2006).

'Faculdade de Ciências Agrárias, Universidade Federal da Grande Dourados (UFGD), Cidade Universitária de Dourados, CP 533, 79804-970, Dourados, MS, Brasil. E-mail: tathianamasetto@ufgd.edu.br. *Autor para correspondência.

"Departamento de Química, Centro de Ciências Exatas, Universidade Estadual de Maringá (UEM), Maringá, PR, Brasil. 
Dentre as plantas daninhas de difícil controle destaca-se o picão-preto (Bidens pilosa L.), que é uma espécie herbácea originária da América Tropical com maior incidência na América do Sul e no Brasil, que está presente em quase todo o território, porém concentra-se nas áreas agrícolas das regiões Sul e Centro-Oeste, nas quais constitui-se uma das mais importantes plantas daninhas de culturas anuais e perenes. A planta é uma invasora bastante agressiva, que além de competir com a cultura pode servir de hospedeiro de pragas e doenças, podendo provocar perdas significativas de produtividade em culturas agrícolas. Sua reprodução ocorre via sementes, seu crescimento é rápido e pode ser encontrada durante todo o ano, mas as maiores infestações ocorrem durante as estações mais quentes, ou seja, primavera e verão (KISSMANN, 1997).

O método de controle mais utilizado para o picão-preto é o químico, pois se a eliminação for mecânica pode-se esperar uma nova geração em poucos dias, visto que o revolvimento do solo traz à superfície sementes com condições de germinar. Além disso, o uso intensivo e indiscriminado de produtos químicos pode ter implicações negativas ao ambiente, à saúde humana e animal, além de representar uma parcela significativa dos custos de produção e da seleção de biótipos tolerantes e resistentes (INOUE et al., 2009).

Como tentativa de controlar a disseminação de plantas invasoras e com a percepção de que as substâncias químicas envolvidas nas interações do tipo planta x planta poderiam ser utilizadas como estratégia de manejo de plantas daninhas, diferentes pesquisas foram desenvolvidos com enfoque no potencial de plantas medicinais. Em síntese, os trabalhos envolvem, em sua fase inicial, o uso de extratos aquosos ou alcoólicos e, em alguns poucos casos, extratos hidroalcoólicos (SOUZA FILHO et al., 2010).

Tropaeolum majus L. (Tropaeolaceae), conhecida popularmente no Brasil como "capuchinha" é originária do Peru, na América do Sul e, desde o século XVII foi introduzida na Europa. A planta é considerada como alimentícia de importância econômica, com ampla utilização medicinal, melífera, corante natural, hortaliça não-convencional e ornamental (CESSA et al., 2009). Na medicina popular brasileira as folhas são utilizadas frequentemente no tratamento de diversas doenças que incluem desordens cardiovasculares, infecções de aparelho urinário, asma e constipação (CORRÊA, 1978; FERREIRA et al., 2004; FERRO, 2006). MAIRESSE et al. (2007) relataram que houve total inibição de extratos de folhas frescas de capuchinha sobre a germinação de sementes de alface (Lactuca sativa L.). Segundo esses mesmos autores os dados de observação devem ser melhores pesquisados para tentar evitar que sinergismos e antagonismos entre os compostos contidos nos extratos possam eliminar espécies promissoras. Desta forma, algumas observações particularizadas para determinados tratamentos devem ser investigadas para a realização de biotestes mais específicos, visando detectar o efeito dos compostos isoladamente.

Até o momento não foram encontrados relatos sobre o efeito de extratos de capuchinha na germinação de plantas daninhas como o picão-preto. Diante disso objetivou-se avaliar o potencial alelopático do extrato metanólico e de frações na germinação das sementes e crescimento inicial de plântulas de picãopreto, por bioensaios em laboratório.

\section{MATERIAL E MÉTODOS}

As plantas de capuchinha foram colhidas no Horto de Plantas Medicinais (HPM), da Universidade Federal da Grande Dourados (UFGD), em Dourados MS, que está situada na região Sul do Estado de Mato Grosso do Sul, com altitude média de $452 \mathrm{~m}$; latitude $22^{\circ} 14^{\prime} 16^{\prime}$ S e longitude 5449'2" W. O clima, segundo a classificação de KÖPPEN (1948) é do tipo Cwa (mesotérmico úmido), com precipitação média anual de $1510 \mathrm{~mm}$ e temperatura média de $22^{\circ} \mathrm{C}$.

O material vegetal (folhas, flores e raízes) foi seco em estufa de ar circulante a uma temperatura de $45 \pm 5^{\circ} \mathrm{C}$ por 48 horas e, posteriormente trituradas separadamente em moinho de faca tipo Willey. Em seguida, as amostras foram submetidas à extração por maceração com metanol, por aproximadamente sete dias em temperatura ambiente, sendo logo após filtradas e concentradas em evaporador rotativo com pressão reduzida, obtendo os extratos metanólicos das folhas, flores e raízes. Posteriormente, o extrato metanólico com melhor potencial de inibição foi submetido a particionamento líquido-líquido com solventes de diferentes polaridades (n-Hexano, clorofórmio e acetato de etila), resultando nas frações hexânica, clorofórmica, acetato de etila e hidrometanólica. O extrato com maior potencial de inibição de picão-preto foi caracterizado pelo espectro de absorção na região do infravermelho (IV) em espectrofotômetro BOMEN, modelo MB-séries, em pastilhas de $\mathrm{KBr}$, na região de 400 a $4000 \mathrm{~cm}^{-1}$ (SILVERSTEIN \& WEBSTER, 2000).

Para avaliar o efeito alelopático dos extratos metanólicos e posteriormente das frações foram utilizadas sementes de picão-preto coletadas no HPM da UFGD, as quais foram previamente desinfestadas com solução de hipoclorito de sódio a $10 \%$ durante 20 minutos e, logo após lavadas em água corrente. 
Os bioensaios foram realizados em placas de Petri ( $9,0 \mathrm{~cm}$ de diâmetro) esterilizadas e revestidas com duas folhas de papel filtro, sendo em seguida acondicionadas em câmara de germinação do tipo B.O.D, regulada a temperatura de $25^{\circ} \mathrm{C}$ e luz branca constantes. Em cada placa foi adicionado $2 \mathrm{~mL}$ do extrato metanólico (1\%), diluídos em solvente (metanol) e, após 24 horas para a evaporação foram adicionados $2 \mathrm{~mL}$ de Tween $80\left(100 \mathrm{mg} \mathrm{mL}^{-1}\right)$ em cada placa. $\mathrm{O}$ tratamento controle (branco) foi realizado com a distribuição das sementes sobre papel germitest umedecido com solução de Tween 80 .

O potencial alelopático dos extratos foi avaliado pela contagem das plântulas normais aos quatro (primeira contagem) e sete dias (contagem final) após a semeadura, sendo consideradas germinadas as sementes com $2 \mathrm{~mm}$ de protrusão radicular. O comprimento da raiz primária e hipocótilo $(\mathrm{cm})$ foi obtido no final do teste, com auxílio de uma régua graduada em milímetros.

O delineamento experimental foi inteiramente casualizado, com três repetições de 25 sementes, utilizando-se no primeiro ensaio, os extratos de folhas, flores e raízes e, no segundo, as frações hexano, clorofórmio, acetato de etila e hidrometanólica, sendo os dados submetidos à análise de variância e comparados pelo teste de Tukey a 5\% de probabilidade, utilizando-se o programa estatístico SISVAR (FERREIRA, 2000).

\section{RESULTADOS E DISCUSSÃO}

Pelos dados da figura 1A observou-se que houve diferença significativa entre as partes da planta de capuchinha sobre a germinação e o crescimento inicial das plântulas de picão-preto, cujos extratos metanólicos preparados a partir das folhas, flores e raízes reduziram a germinação das sementes em relação as que foram imersas em Tween-água. Com relação aos dados de primeira contagem observou-se menor percentual de germinação (30\%) nas sementes de picãopreto semeadas no substrato contendo o extrato metanólico das folhas em relação às sementes submetidas aos extratos de raízes (68\%) e flores (78\%), para as quais também houve redução na germinação quando comparadas com aquelas que não foram submetidas ao ensaio alelopático (87\%).

Aos sete dias após a semeadura observouse que o extrato das flores não inibiu a germinação (96\%) e foi superior as sementes do tratamento controle (95\%), não diferindo estatisticamente. A análise permitiu inferir que a germinação não foi impedida, apenas retardada; entretanto constatou-se o potencial fitotóxico das raízes e das folhas de capuchinha sobre a germinação, sendo o das folhas mais intenso sobre a formação de plântulas normais de picão-preto (38\%).

A germinação é menos sensível aos aleloquímicos do que o crescimento da plântula (FERREIRA \& BORGHETTI, 2004), porém, a quantificação experimental é muito mais simples, pois, para cada semente, o fenômeno é discreto, germinando ou não. Nesse contexto, substâncias alelopáticas podem induzir o aparecimento de plântulas anormais, sendo a necrose da raiz um dos sintomas mais comuns.

Sementes de picão-preto submetidas aos extratos de folhas (BORELLA \& PASTORINI, 2009) e de frutos de umbu (Phytolacca dioica L.) (BORELLA $\&$ PATORINI, 2010) não germinaram, provavelmente devido a presença de flavonóides nos frutos. De acordo com HOFFMANN et al. (2007) sementes de picão-preto tiveram a porcentagem e o índice de velocidade de germinação significativamente reduzidos devido à ação de extratos aquosos de comigo-ninguém-pode (Dieffenbachia picta Schott). CORSATO et al. (2010) observaram o efeito inibitório de folhas frescas de girassol (Helianthus annus L.) sobre a germinação de sementes de picão preto e relataram que os terpenos podem não ter sido os responsáveis pelo expressivo efeito inibitório do girassol sobre as sementes de picão preto, enquanto outras substâncias presentes nas folhas, como os flavonóides (substâncias solúveis em água) podem ter ocasionado esse resultado.

Os efeitos dos extratos de capuchinha sobre o comprimento da raiz primária (Figura 1B) e do hipocótilo das plântulas (Figura 1C) variaram em relação àqueles encontrados para a germinação das sementes do picão-preto (Figura 1A). Diferentemente do bioensaio para a germinação, a intensidade dos efeitos sobre o picão-preto não diferiu estatisticamente entre raiz e folha, embora ainda fossem mais intensos que $o$ extrato metanólico da flor sobre o crescimento inicial da plântula. Segundo HOFFMANN et al. (2007), o aumento gradativo das concentrações de extratos aquosos de espirradeira (Nerium oleander $\mathrm{L}$.) também reduziram significativamente o comprimento radicular e da parte aérea de plântulas de picão-preto.

Compostos alelopáticos como os ácidos vanílico e gálico presentes no extrato da parte aérea de mourisco (Fogopyrum esculentum Moench) foram sugeridos por MORAES et al. (2010) como os responsáveis pela redução da germinação e do crescimento de plântulas de picão-preto, pois muitas vezes, mesmo germinando, a plântula não consegue vencer as interferências e se desenvolver. A análise do vigor da plântula recém-formada pode prever o sucesso ou o fracasso do crescimento de uma espécie (FERREIRA\& BORGHETTI, 2004).

Ciência Rural, v.42, n.1, jan, 2012. 


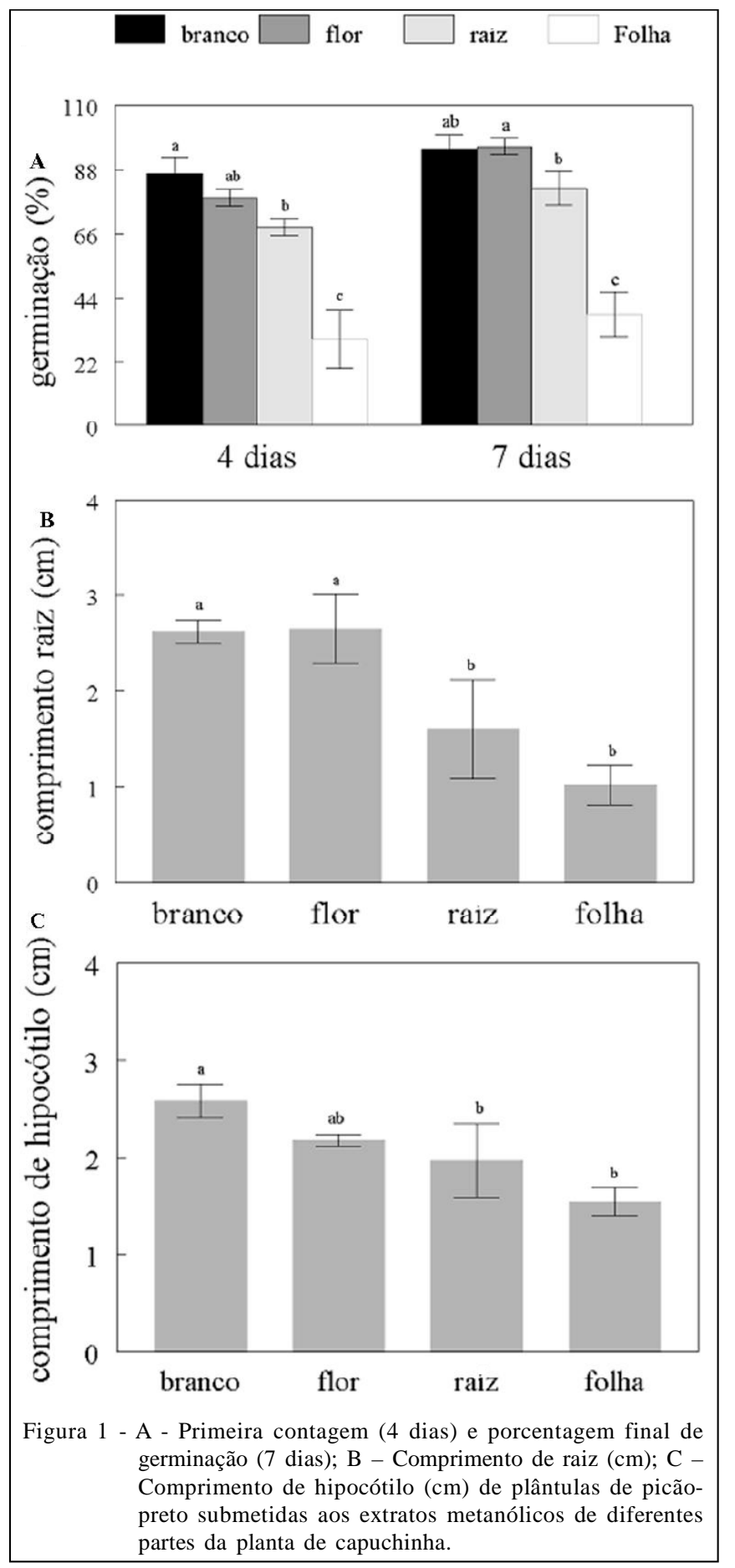

Mesmo não se observando diferença estatística entre os extratos das raízes e folhas sobre o comprimento de hipocótilo e raiz primária de plântulas de picão-preto, o crescimento daquelas submetidas ao extrato da folha foi afetado negativamente, com comprimento de raiz e hipocótilo inferiores a 1,1 e 1,5cm, respectivamente, quando comparados com o das plântulas imersas na água. A análise da germinação na primeira contagem e no final do teste evidenciou que as folhas de capuchinha tiveram efeito inibitório mais acentuado do que as demais partes da planta, ou seja, foram a principal fonte de substâncias potencialmente alelopáticas.

$\mathrm{Na}$ tentativa de caracterização dos componentes responsáveis pela inibição, o extrato 
metanólico das folhas foi submetido a particionamento e, a medida que se aumentou a polaridade dos solventes, ou seja, foram extraídos os compostos mais polares verificou-se maior efeito inibitório sobre a germinação (Figura 2A) e o crescimento das plântulas de picão-preto (Figura 2B) e, a partir da repartição ocorreu a redução da sinergia dos componentes. As sementes de picão-preto submetidas às frações acetato de etila e hidrometanólica não diferiram estatisticamente entre si e expressaram os menores resultados de germinação na primeira contagem (38 e $31 \%$, respectivamente) e na contagem final do teste $(50 \mathrm{e}$ $46 \%$, respectivamente). As frações hexânica e clorofórmica foram menos intensas sobre as sementes de picão-preto, cuja germinação na primeira contagem foi de 51 e $55 \%$, respectivamente e, porcentagem final de germinação de 75 e 58\%, respectivamente (Figura 2A). Para o comprimento de raiz e hipocótilo das plântulas, as frações clorofórmica, acetato de etila e hidrometanólica não diferiram estatisticamente entre si, com maior efeito inibitório em relação à fração hexânica e ao tratamento controle (Figura 2B).

De maneira geral, no espectro de infravermelho (IV) do extrato metanólico das folhas (Figura 3) constatou-se absorções na região de 3.381 $(\mathrm{OH})$, referente à deformação axial em hidrogênio intermolecular aromático, 3.010 (C-H aromático), 2.923 a 2.852 (C-H em composto alifático), $1741(\mathrm{C}=\mathrm{O}), 1460$ a $1065 \mathrm{~cm}^{-1}$ (deformação angular $\mathrm{CH}_{2}, \mathrm{CH}_{3}$, deformação axial $\mathrm{C}=\mathrm{C}$, deformação axial $\mathrm{CH}_{3}-\mathrm{CO}$, deformação axial $\mathrm{C}-\mathrm{O})$.

Várias substâncias químicas relacionadas com alelopatia têm sido descritas em detalhes por autores como WHITTAKER \& FEENY (1971), RICE (1984) e PUTNAM \& TANG (1986). Relatos da literatura demonstraram a presença de ácidos graxos

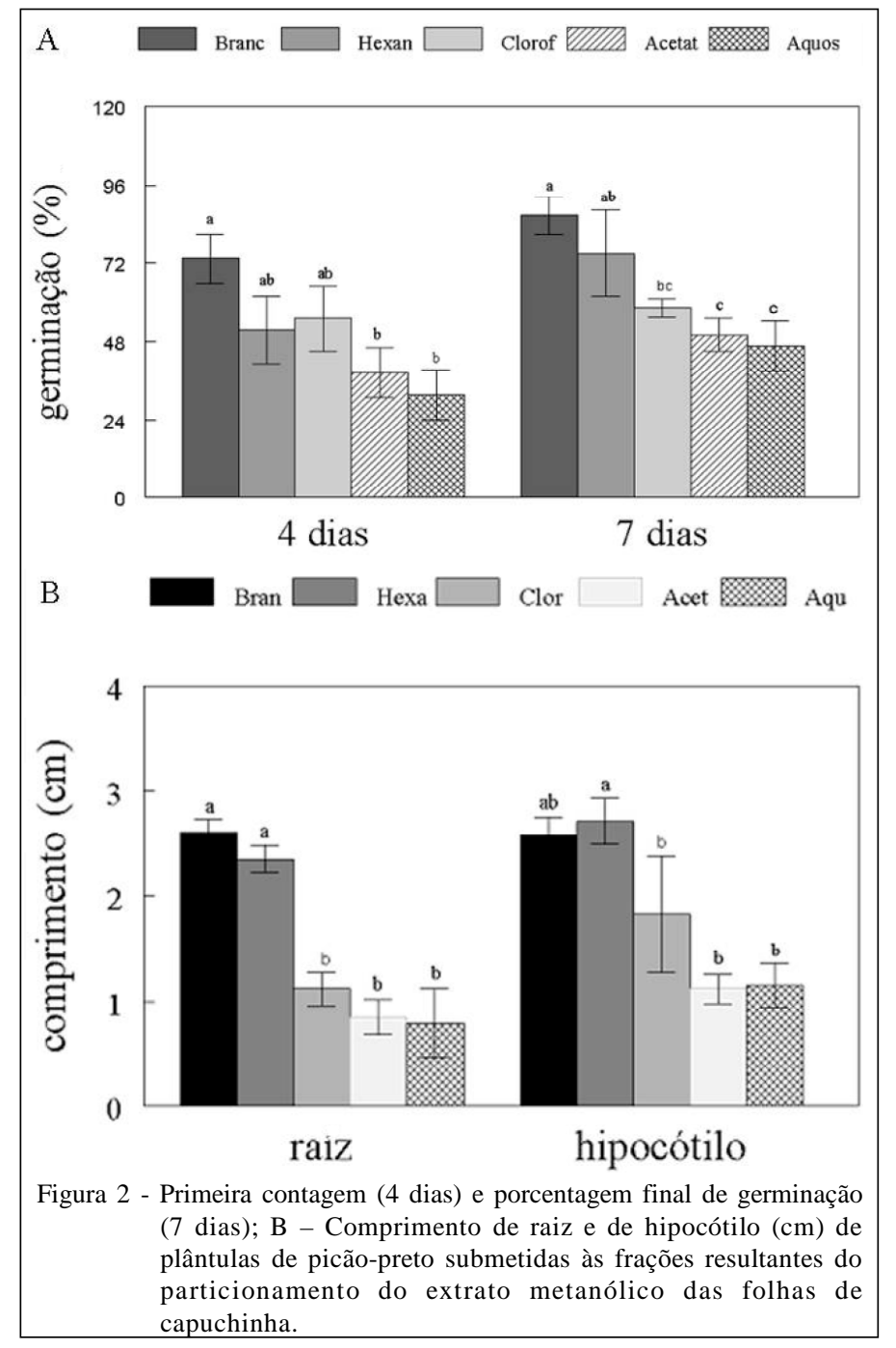

Ciência Rural, v.42, n.1, jan, 2012. 


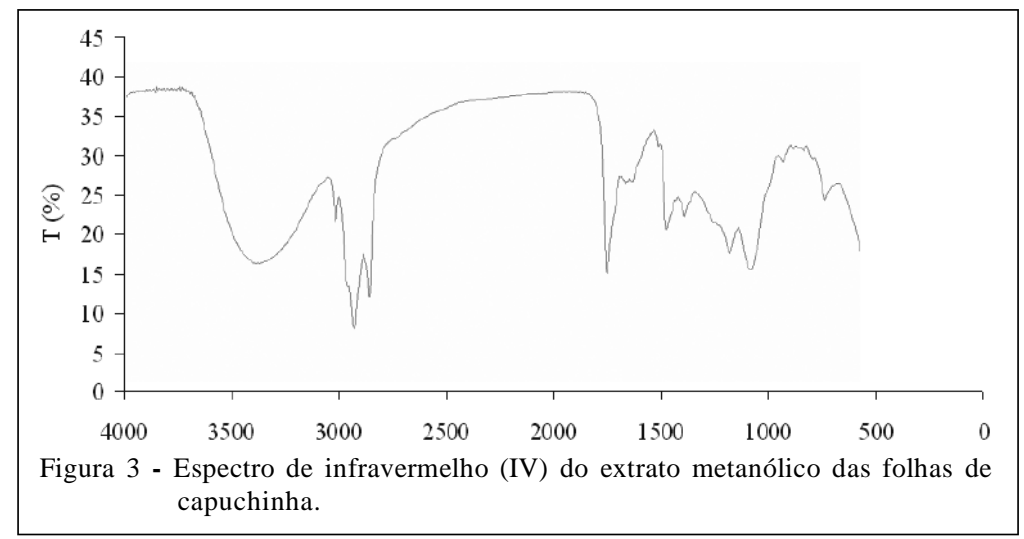

(erúcico, oléico e linoléico), esteróides, saponinas e flavonóides (isoquercitrosídio, quercetol 3triglucoside e canferol glucoside) nas sementes e folhas de capuchinha (De MEDEIROS et al., 2000; MIETKIEWSKA et al., 2004; ZANETTI et al., 2004). Glucosinolatos (benzilglucosinolatos), como glucotropaeolina sinalbina e os triterpenos tetracíclicos cucurbitacinos foram isolados previamente das folhas desta planta (LYKKESFELDT \& MELLER, 1993; GRIFFITHS et al., 2001).

Diante do potencial alelopático inibitório das folhas de capuchinha e da presença de compostos com tais propriedades sugere-se a realização de novas pesquisas como a purificação das frações e o isolamento dos compostos para a confirmação da atividade fitotóxica das folhas de capuchinha sobre o estabelecimento de picão-preto.

\section{CONCLUSÃO}

A maior atividade fitotóxica de capuchinha é das folhas sobre a germinação e o crescimento inicial das plântulas de picão preto, destacando após o particionamento, as frações clorofórmica, acetato de etila e hidrometanólica;

A análise do infravermelho indica a presença de substâncias com grupos hidroxila, anel aromático, grupos alifáticos, carbonilas, grupos $\mathrm{C}=\mathrm{C}$ e ligações C-O de álcoois, éteres ou ésteres.

\section{REFERÊNCIAS}

BORELLA, J.; PASTORINI, L.H. Influência alelopática de Phytolacca dioica L. na germinação e crescimento inicial de tomate e picão-preto. Biotemas, v.22, n.3, p.67-75, 2009. Disponível em: <http://www.biotemas.ufsc.br/volumes/pdf/ volume223/67a75.pdf?q=picao>. Acesso em: 12 abr. 2011.

BORELLA, J.; PASTORINI, L.H. Efeito alelopático de frutos de umbu (Phytolacca dioica L.) sobre a germinação e crescimento inicial de alface e picão-preto. Ciência e
Agrotecnologia, v.34, n.5, p.1129-1135, 2010. Disponível em: 〈http://www.scielo.br/pdf/cagro/v34n5/08.pdf>. Acesso em: 22 abr. 2011.

CESSA, R.M.A. et al. Produção de capuchinha cultivada em vaso com diferentes doses de fósforo e potássio em casa de vegetação. Global Science Technology, v.2, n.3, p.1-07, 2009. Disponível em: <http://www.cefetrv.edu.br/periodicos/ index.php/gst/article/viewArticle/34>. Acesso em: 02 abr. 2011.

CORSATO, J.M. et al. Efeito alelopático do extrato aquoso de folhas de girassol sobre a germinação de soja e picão-preto. Semina: Ciências Agrárias, v.31, n.2, p.353-360, 2010. Disponível em: <http://www.uel.br/revistas/uel/index.php/semagrarias/article/ viewArticle/5306>. Acesso em: 30 maio, 2011.

CORRÊA, M.P. Dicionário das plantas úteis do Brasil e das exóticas cultivadas. Rio de Janeiro: Imprensa Nacional, 1978. V.II, 67p.

DE MEDEIROS, J.M.R. et al. Antithrombin activity of medicinal plants of the Azores. Journal of Ethnopharmacology, v.72, n.12, p.157-165, 2000. Disponível em: <http://www.sciencedirect.com/ science/article/pii/S0378874100002269>. Acesso em: 20 maio, 2011. doi: 10.1016/S0378-8741(00)00226-9.

FERREIRA, D.F. SISVAR sistema para análise de variância. Lavras: Universidade Federal de Lavras (Departamento de Ciências Exatas DEX), 2000. (CD-ROM).

FERREIRA, R.B.G. et al. Análise de crescimento de Tropaeolum majus 'jewel' em função de espaçamentos entre plantas. Revista Brasileira de Plantas Medicinais, v.7, n.1, 57-66, 2004. Disponível em: <http://www.ibb.unesp.br/servicos/publicacoes/ rbpm/pdf_v7_n1_2005/artigo_11_v7_n1.pdf>. Acesso em: 05 fev. 2011.

FERREIRA, A.G.; BORGHETTI, F. Germinação: do básico ao aplicado. Porto Alegre: Artmed, 2004. 323p.

FERRO, D. Fitoterapia: conceitos clínicos. São Paulo: Atheneu, 2006. 410p.

GRIFFITHS, D.W. et al. Identification of glucosinolates on the leaf surface of plants from the Cruciferae and other closely related species. Phytochemistry, v.57, n.5, p.693-700, 2001. Disponível em: <http://www.sciencedirect.com/science/article/ pii/S0031942201001388>. Acesso em: 12 fev. 2011. doi: 10.1016/S0031-9422(01)00138-8. 
HOFFMANN, C.E.F. et al. Atividade alelopática de Nerium Oleander L. e Dieffenbachia picta schott em sementes de Lactuca Sativa L. e Bidens pilosa L. Revista de Ciências Agroveterinárias, v.6, n.1, p.11-21, 2007. Disponível em: <http://rca.cav.udesc.br/rca_2007_1/hoffmann.pdf >. Acesso em: 12 fev. 2011.

INOUE, M.H. et al. Extratos aquosos de Xylopia aromatica e Annona crassiflora sobre capim-marandu (Brachiaria brizantha) e soja. Scientia Agraria, v.10, n.3, p.245-250, 2009. Disponível em: <http://ojs.c3sl.ufpr.br/ojs2/index.php/ agraria/article/viewArticle/14509>. Acesso em: 10 fev. 2011.

KISSMANN, G.K. Plantas daninhas e nocivas. 2.ed. São Bernardo do Campo: BASF Brasileira, 1997. Tomo 1, 825p.

KÖPPEN, W. Climatologia: com um estúdio de los climas de la tierra. México: Fondo de Cultura Econômica, 1948. 478p.

LYKKESFELDT, J.; MELLER, B.L. Synthesis of benzylglucosinolate in Tropaeolum majus L. Plant Physiology, v.102, n.2, p.609-613, 1993. Disponível em: <http://www.plantphysiol.org/content/102/2/609.short>. Acesso em: 09 fev. 2011. doi: 10.1104/pp.102.2.609.

MAIRESSE, L.A.S. et al. Bioatividade de extratos vegetais sobre alface (Lactuca sativa 1.). Revista da Faculdade de Zootecnia, Veterinária e Agronomia, v.14, n.2, p.1-12, 2007. Disponível em: <http:revistaseletronicas.pucrs.br/ojs/ index.php/fzva/article/view/2494>. Acesso em: 06 fev. 2011.

MIETKIEWSKA, E. et al. Seed-specific heterologous expression of a nasturtium FAE gene in Arabidopsis results in a dramatic increase in the proportion of erucic acid. Plant Physiology, v.136, n.1, p.2665-2675, 2004. Disponível em: <http://www.plantphysiol.org/content/136/1/2665.short>. Acesso em: 29 maio, 2011. doi: 10.1104/pp.104.046839.

MORAES, P.V.D. et al. Potencial alelopático de extratos aquosos de mourisco (Fogopyrum esculentum Moench) na germinação e crescimento inicial de plantas daninhas. Revista Tropical Ciencias Agrárias e Biológicas, v.4, n.3, p.10, 2010. Disponível em: <http://gurupi.ufma.br/index.php/ccaatropica/ article/view/89>. Acesso em: 09 maio, 2011.

PUTNAM, A.R.; TANG, C.S. Allelopathy: state of the science. In: PUTNAM, A.R.; TANG, C.S. (Eds.). The science of allelopathy. New York: John Wiley \& Sons, 1986. p.1-19.

RICE, E.L. Allelopathy. 2.ed. New York: Academic, 1984. $422 p$.

SILVA, S.O. et al. Diversidade e frequência de plantas daninhas em associações entre cafeeiros e grevileas. Coffee Science, v.1, n.2, p.126-134, 2006. Disponível em: <http:// www.coffeescience.ufla.br/ojs/index.php/Coffeescience/article/ viewArticle/28>. Acesso em: 21 maio, 2011.

SILVERSTEIN, R.M.; WEBSTER, F.X. Identificação espectrométrica de compostos orgânicos. 6.ed. Rio de Janeiro: LTC, 2000. 480p.

SOUZA FILHO, A.P.S. et al. Atividade alelopática de extratos brutos de três espécies de Copaifera (LEGUMINOSAECAESALPINIOIDEAE). Planta Daninha, v.28, n.4, p.743751, 2010. Disponível em: <http://www.scielo.br/pdf/pd/v28n4/ v28n4a06.pdf $>$. Acesso em: 17 maio, 2011.

WHITTAKER, R.H.; FEENY, P.P. Allelochemics: chemical interaction between species. Science, v.171, n.3973, p.757770, 1971. Disponível em: 〈http://www.sciencemag.org/ content/171/3973/757.short>. Acesso em: 13 set. 2010. doi: 10.1126/science.171.3973.757.

ZANETTI, G.D. et al. Análise morfo-anatômica de Tropaeolum majus L. (Tropaeolaceae). Iheringia Série Botânica, v.59, n.2, p.173-178, 2004. Disponível em: <http://www.fzb.rs.gov.br/ publicacoes/iheringia-botanica/Ih59-2-p173-178.pdf>. Acesso em: 10 nov. 2010. 